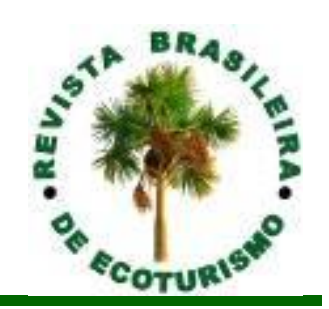

\title{
Governança ambiental e turismo no Parque Nacional da Amazônia
}

\author{
Environmental governance and tourism in Amazon National Park
}

Mônica de Nazaré Ferreira de Araújo, Ligia Terezinha Lopes Simonian

\section{RESUMO}

Neste artigo, apresenta-se e discute-se o processo de governança ambiental do Parque Nacional da Amazônia. O foco de análise foi orientado para as entrevistas realizadas com os membros do conselho consultivo desta Unidade de Conservação (UC) brasileira, bem como para o arranjo institucional de participação da sociedade na sua gestão. Ainda, discutem-se as ações coletivas de turismo empreendidas no Parque, a formação desse conselho, os problemas enfrentados na administração desta UC e as condições atuais da mesma. Dentre os resultados da pesquisa, estão a desarticulação do conselho, o anúncio da construção do Complexo Hidrelétrico do Tapajós e, como consequência, um estado de (des)governança.

PALAVRAS-CHAVE: Governança ambiental; Turismo; Ação coletiva.

\begin{abstract}
In this article, it is presented and discussed the process of environmental governance process of the Amazon National Park. The focus of the analysis was oriented to the interviews done with members of the advisory council of this Brazilian Protected Area (PA), as well as to the institutional arrangement of the society participation in its management. Yet, it is also discussed the collective actions of tourism undertaken in the Park, the formation of this council, the problems faced in the administration of this PA and its current conditions. Among the research's results are the dismantling of the advisory board and the announcement of the construction of the Tapajos Hydroelectric Complex and, as a consequence, a state of (un)governance.
\end{abstract}

KEYWORDS: Environmental governance; Tourism; Collective ation.

\section{Introdução}


O mundo amazônico é de uma multiplicidade/complexidade que enche o olhar e ao mesmo tempo espanta pelo emaranhado de situações a compreender, assim, de homogeneidade nele pouco se encontra. Sua biodiversidade em fauna e flora é das mais ricas e complexas do planeta, sem falar nas suas extensões e massas aquíferas. Não por acaso, hoje o cone norte capitalista e desenvolvido volta-se com os mais variados interesses para essa região do Brasil - apesar de historicamente ter sido território de exploração e disputa por nações de ponta.

Ao tecer considerações sobre os interesses internacionais do capitalismo pela Amazônia brasileira, De Antoni (2010) faz uma digressão histórica, baseado em três momentos crucias: em primeiro lugar, o ciclo da borracha, em seguida, a ampliação da fronteira amazônica e, por último, a concepção e realização dos projetos de porte grande. Apenas para situar o Brasil e sua região amazônica dentro desse processo, esse caminho pode constituir-se em uma orientação.

Com relação à fase inicial (1840), segundo De Antoni (2010), o Brasil assumiu uma posição central devido à demanda grande da Hevea brasiliensis, importante fonte de matéria prima para o processo de vulcanização e de pneumáticos. Num segundo momento (1830-1980), a Amazônia com a expansão da sua fronteira, tornou-se elemento-chave para o desenvolvimento do país, quando então, é objeto de um planejamento regional.

E o último momento (anos de 1980) pode ser visto por dois projetos de envergadura: o Programa de Desenvolvimento da Região Noroeste (POLONOROESTE) e o Programa Grande Carajás (PGC). Ainda conforme o autor, tanto um projeto quanto outro sofreu críticas de parte de movimentos ambientalistas preocupados com a proteção ao meio ambiente e com as ameaças aos indígenas. Diante desse cenário de pressão internacional, o Banco Mundial juntamente com seus parceiros foi levado a impor uma avaliação crítica que culminou, em 1985, com a suspensão de financiamento desses projetos. De Antoni (2010) ainda conclui que

A força do movimento ambientalista internacional, particularmente amplificada pelos meios de comunicação ocidentais depois da morte de Chico Mendes, parecia oferecer o momento oportuno para reconsiderar a importância do meio ambiente e das populações tradicionais nas políticas econômicas regionais e mundiais [...] (DE ANTONI, 2010, p. 303).

Esses três momentos, portanto, podem ser considerados marcos de um desenvolvimento econômico brasileiro, que em síntese, lançou o Brasil no cenário das relações capitalistas internacionais, culminando, em uma fase nova de globalização.

Como uma fênix que renasce das cinzas e diante de desafios, o capitalismo mundial quase sempre encontra soluções que o façam respirar e mover rumo a estruturas novas. Nessa perspectiva, Silva (2007) ressalta que: 
A ameaça ecológica fazia parte do cenário turbulento que poderia comprometer o padrão produtivista ocidental, fundado numa racionalidade econômica, que tem como lógica a necessidade crescente de recursos naturais, a natureza servindo de suporte material, no sentido "utilitarista" para produção de mercadorias (SILVA, 2007, p. 82).

Dentro de tal contexto, a "saída" criada pelo capitalismo configurado no bloco de poder hegemônico mundial, foi definir uma governança ambiental global em torno da Amazônia. Isso para preservar e dar continuidade ao modo de produção ocidental, de acordo com a ideologia economia neoclássica, que entende os recursos naturais precipuamente como mercadoria.

Isso se expressa por conexões novas entre economia e política nos contextos nacional e internacional (financiamentos descentralizados). Também, tal perspectiva passa por uma concepção nova do papel do Estado, por uma sobrevalorização da natureza e por uma velocidade maior de transformação das atividades e dos territórios por efeito das redes técnicas (BECKER, 2004). Todavia para essa autora,

O novo valor atribuído ao potencial de recursos naturais confere à Amazônia o significado de fronteira do uso-científico tecnológico da natureza e, em sintonia com a política da formação de grandes blocos supranacionais, revela a necessidade de pensar e agir na escala da Amazônia sul-americana (BECKER, 2004, p. 33-34).

Segundo essa visão de globalização do mundo capitalista, reconhece-se um singular significado à questão ambiental na região amazônica, o qual está intrinsecamente associado à configuração geopolítica mundial desses últimos anos.

Foi nos anos iniciados em 1990, como referente de sustentabilidade, que o país alçou-se mundialmente como protagonista da parceria transnacional no que diz respeito às especificidades da biodiversidade amazônica enquanto espaço impactante sobre o meio ambiente do planeta Terra. Nessa direção e nos termos de Silva (2007),

A região é foco de interesses de forças políticas e movimentos locais, nacionais e transnacionais. Por isso, tem se projetado como palco estratégico de emergentes e expansivas rede de estados, grupos empresariais e organizações da sociedade civil, na perspectiva de alcançar uma condição de segurança e desenvolvimento sustentável que promova a integração regional à dinâmica do capitalismo nacional e internacional (SILVA, 2007, p. 80).

Pelo exposto, nota-se a emergência de um embrião de governança ambiental na Amazônia que, a partir desse momento histórico, vai cada vez mais consolidarse como estratégia imprescindível para a proteção do seu meio ambiente. 
Neste artigo, tem-se por objetivo analisar o processo de governança ambiental do Parque Nacional da Amazônia (PARNAMAZONIA) no que respeita às ações de turismo a partir de um dos elementos responsáveis pela instância de gestão, ou seja, o conselho consultivo (CC). Também, discutem os problemas de continuidade na articulação dos partícipes desse CC e suas consequências para esta Unidade de Conservação (UC).

Entretanto, cabe aqui ressaltar que a Amazônia é, conforme Nascimento e Simonian (2014), uma região que precisa ser refletida a partir de suas singularidades. E no que se refere a sua política pública de turismo, esta deveria ser planejada e implementada com a participação efetiva de seus atores sociais e por meio de institucionalidades novas, sobretudo, tripartites.

\section{Localização/breve caracterização da área de estudo e metodologia}

Reconhecido como Unidade de Proteção Integral (UPI), o PARNAMAZONIA foi criado em 19 de fevereiro de 1974, pelo Decreto n‥ 73.683, como parte do Programa de Integração Nacional (PIN); isso ocorreu logo após a construção da Transamazônica, BR-230. Segundo o Instituto Chico Mendes de Conservação da Biodiversidade (ISA, 2011) está localizado no sudoeste do Pará e nordeste do Amazonas, às margens do Tapajós, principal rio que drena a área e faz parte do mosaico de UC da BR-163.

Pelas informações de Kasecker (2011), o PARNAMAZONIA abrange os municípios de Itaituba e Aveiro (PA), além de Maués (AM) e

[...] faz fronteira ao norte com a Terra Indígena Andirá-Marau, a leste com a Floresta Estadual de Maués e com a Floresta Nacional do Pau-Rosa, e ao sul com a Floresta Nacional do Amana. Os limites desta unidade de conservação foram definidos pelo Decreto 73.683 [...], com uma área inicial de 994.000 hectares. Em 2006, através do Decreto SN de 13 de fevereiro, o Governo Federal aumentou a área do parque para mais de um milhão de hectares (KASECKER, 2011, p. 92).

De acordo com o Instituto Socioambiental (ISA, 2011), o PARNAMAZONIA conta atualmente com uma área de 1.089.436 hectares, conforme consta na Lei no . 12.678, de, 25 de junho de 2012, que fora assinada pela presidenta Dilma Rousseff. À guisa de uma compreensão atualizada sobre essa área e de acordo com informações evidenciadas no campo, constatou-se que a área sofreu uma desafetação em decorrência do projeto de implantação da Hidrelétrica de São Luiz do Tapajós ${ }^{1}$. Aliás, está prevista sua construção para esse ano de 2016.

A se pensar os aspectos referentes ao comportamento e a caracterização geral dos visitantes do PARNAMAZONIA, têm-se quatro estratos, conforme Estratégia (2009) e ICMBIO (2014).

a) Grupo de estudantes: segundo informações repassadas pelos condutores de turismo (vigilantes), dentre os estudantes que frequentam o parque, a sua maioria vem pela primeira vez. São estudantes de ensino médio de faixas etárias diversas, inclusive a de terceira idade. 
b) Peregrinos: é de Itaituba a maioria dos visitantes que se dirigem à Capelinha de São José da Mata. Normalmente, são senhores e senhoras na faixa etária dos sessenta anos

c) Turistas nacionais e estrangeiros: já era de esperar-se que a biodiversidade grandiosa do parque não fosse de interesse apenas de brasileiros, 0 que pode ser constatado pela regularidade do fluxo de turistas estrangeiros.

d) Observadores de aves (birdwatchers): em geral, são ingleses, alemães e norte-americanos, os principais estrangeiros que para o parque se dirigem como o intuito de observar suas aves. Predominantemente, esses visitantes têm idade superior a 55 anos.

e) Recreativos (piqueniques): as visitas dessa categoria acontecem sem regularidade, de quando em quando, pelos moradores locais, como também por estudantes. Nessas ocasiões, os moradores que frequentam a base são parte da família e do círculo de amizade dos vigilantes, que nessa categoria constituem-se nos usuários principais.

No que se refere à metodologia, além da realização da pesquisa bibliográfica e documental, fez-se um survey em março de 2012 e uma pesquisa de campo em setembro de 2013, ambas em Itaituba (PA). Nesse contexto, foram priorizadas entrevistas semiestruturadas com interlocutores-chave e alguns membros do CC do PARNAMAZONIA.

Do universo de 21 componentes do CC do PARNAMAZONIA, foram entrevistados 13. Desses, cinco eram de instituições governamentais e oito de entidades não governamentais. Nesse sentido, acredita-se que foi possível levantar e registrar elementos fundamentais para as análises quanto aos objetivos do estudo em questão.

\section{Governança ambiental: alguns aspectos históricos e teóricos}

A sustentabilidade ambiental tem sido vista como cerne de convergências de forças para o desenvolvimento dentro de um sistema produtivo que tenha como base eficiência de energia, que recicle materiais, controle os níveis de poluição e tenha uma face ecológica (VIOLA, 1998). E o foco em um desenvolvimento sustentável na Amazônia que implique uma mudança robusta de sentido da política de desenvolvimento, a qual há de fundamentar-se em estímulos à produção sustentável que contenha uma tecnologia eficaz e que também seja aberta ao capital e à cooperação internacional. $O$ autor aduz, ainda, que

Neste esquema o zoneamento ecológico-econômico e as jointventures Estado-corporações transnacionais ocupam um lugar estratégico dividindo-se a Amazônia em quatro grandes subsistemas: áreas de desenvolvimento sustentável de alta tecnologia, áreas de desenvolvimento sustentável de limitada tecnologia/extrativismo, áreas de preservação/turismo ecológico e áreas de preservação radical (VIOLA, 1998, p. 20, grifo das autoras). 
Nesse panorama e dentre ouras possibilidades, é fundamental pensar-se, o turismo na contemporaneidade, em especial no que ele pode proporcionar de contribuição, a partir de uma arquitetura de governança para um desenvolvimento sustentável.

Para refletir nesses termos, é imprescindível que se volte o olhar às relações entre democracia e governança para um turismo que seja, no sentido de sucesso, associado a uma perspectiva maior de sustentabilidade. No entanto, é mister que se faça uma digressão histórica sobre o que significou para o Brasil o processo de redemocratização política. Sem dúvida, isso vai reverberar positivamente nos arranjos institucionais necessários à estruturação da governança em áreas protegidas.

Isso fica bem evidente quando se consulta Araújo e Castro (2007), pois ambos argumentam que " $A$ sociedade civil passou então a ser vista como lócus para as transformações políticas necessárias a um novo ordenamento que possibilite a expressão dos diversos setores e segmentos sociais" (ARAUJO; CASTRO, 2007, p. 11). Essa assertiva vai se revelar quando da necessidade de se construir uma governança democrática que vai pressupor uma ordem dependente de uma gama enorme de atores sociais envolvidos na questão das áreas protegidas. Os autores consolidam tal afirmação ao dizerem que

As pressões dos movimentos sociais cumpriram papel fundamental na transição do país rumo à democracia. A estrutura centralizadora no processo decisório do país passou a ser por eles questionada, pois impedia o acesso dos segmentos organizados da sociedade às definições públicas e ao controle dos gastos públicos, o que resultou na exigência de mudanças nas instituições do Estado, para que abrigassem o controle mais direto das representações da sociedade (ARAÚJO; CASTRO, 2007, p. 11).

Adjunto à emergência dessa mobilização social, é importante que se informe que, à época, o Brasil estava em crise econômica, e sua legitimidade de poder estava em xeque, o que obrigou a administração pública criar mecanismos estratégicos que levariam a uma descentralização das políticas e das ações.

O processo de redemocratização no Brasil culminou em termos políticos com o advento da Constituição de 1988, que em seu artigo 1․․ prevê que: "Todo poder emana do povo, que o exerce indiretamente através de seus representantes eleitos, ou indiretamente, nos termos desta Constituição" (BRASIL, 1988, p.23). Nesse sentido, é a partir desse princípio democrático que se inaugura um momento histórico novo quanto à inserção da sociedade nos contextos de cidadania e nos processos decisórios que dizem respeito à "coisa pública".

A partir da década de noventa, foram intensificados os estudos sobre governança. Agora, o olhar "debruça-se" sobre uma série de questões de natureza social e política. No espectro socioambiental, de acordo com Fuentes (2011) a contemporaneidade dá ênfase à "governança florestal", "governança energética", "governança dos recursos naturais" - sobretudo, "governança da água" -, governança de áreas protegidas, entre outros campos. Foram articulados enfoques 
conceituais como também marcos "prescritivos" sobre a "boa governança", incluindo não somente marcos regulatórios, transparências, prestação de contas.

Desse modo, a governança ambiental pode ser expressa via três dimensões: a "governança dos recursos naturais", a "governança indígena"3 e a "governança de áreas protegidas". Evidencia-se, assim, que o termo governança pode compreender, em sua visão macro, várias esferas, quais sejam, local, regional, nacional e global (ANDRADE-MENDONZA, 2011). Na governança de áreas protegidas (AP), o conceito foi fortalecido, no início dos anos de 1990 quando emergiram demandas oriundas de setores diferentes, tais como os povos indígenas, governos locais, coletivos, instituições e organizações não governamentais que demandaram do Estado institucionalidades novas. $\mathrm{Na}$ concepção de Fuentes (2011, p. 85-86), isso resultou na criação de um "sistema normativo internacional" no que respeita às AP.

Na discussão sobre governança ambiental, Jacobi e Sinisgali (2012) enfatiza que esta abre espaço instagador para se repensar modalidades inovadoras de gestão, pois integram o sistema de governança determinados elementos-vetores de articulações. Tais, balizadores seriam: o político - que vai dar o equilíbrio necessário aos diversos interesses e realidades, credibilidade, fator preponderante para que as pessoas confiem nas políticas a serem adotadas - e, por último, a dimensão ambiental.

Assim, baseada nesses três pilares, a governança ambiental é, no entendimento de Jacobi e Sinisgali (2012, p.1472), um "[...] exercício deliberado e contínuo de desenvolvimento de práticas cujo foco analítico está na noção de poder social, que medeia [sic] as relações entre Estado, Sociedade Civil, mercados e o meio ambiente". Abstrai-se daí, que a governança ambiental amplia e consolida o arco de articulações em torno de problemas socioambientais, dado sua capilaridade influenciadora na construção de soluções para as demandas socioambientais.

Nessa direção, Irving e Loureiro (2007) comentam, conclusivamente, no que se tem de perspectivas novas para a formação de uma governança mais efetiva e eficaz e de premências coletivas determinadas. A saber, Irving e Loureiro (2007, p. 10) esclarecem que

[...] institui-se a possibilidade de criação de meios de participação da sociedade (plebiscito, referendo, iniciativa popular de lei, audiências públicas, conselhos, comitês, fóruns, orçamento participativo, ouvidorias etc.). Esses são os principais instrumentos de uma nova governança, em formação, nos quais se inserem os conselhos de gestão de áreas protegidas.

Por conselho, Gohn (2003) define como sendo "[...] canais de participação que articulam representantes da população e membros do poder público estatal, em práticas que dizem respeito a gestão de bens públicos [...]. (GOHN, 2003, p. 7). No entanto, apesar da institucionalização desses meios legítimos de participação social, Araújo e Castro (2007) afirmam que 
[...] as estruturas políticas e a cultura institucional nos estados e municípios permaneciam as mesmas. Era, então, necessário investir na democratização dessas estruturas para que o objetivo inicialmente perseguido pelos movimentos sociais e setores organizados da população pudesse de fato ser alcançado (ARAÚJO; CASTRO, 2007, p. 12).

A seguir esse raciocínio, o processo de redemocratização não termina com a constituição de uma Carta Magna nova. É no embate das ideias conjuntamente com as necessidades e imperativos do cotidiano que as arquiteturas verdadeiramente democráticas vão se moldando e atingindo objetivos coletivos determinados. Ao voltar-se a se debruçar sobre o espaço criado pela Constituição no que diz respeito à participação popular quando o país retoma seu processo de democratização, e tendo como finalidade o processo de governança em UC, depara-se com a instituição do que se chama CC. Nesse âmbito de análise, de acordo com o SNUC, os conselhos gestores têm dupla natureza, ou seja, uma, consultiva, outra, deliberativa. Especificamente no que diz respeito aos parques, esses conselhos são consultivos.

Diante dessa constatação, fica cabal que a multiplicidade de atores na composição dos CC somente torna-se um espaço de potencialidades tangentes à formação de uma governança se houver sinergia de interesses para o cumprimento de um objetivo. Por fim, é importante ressaltar, seguindo as palavras de IRVING et al. (2005, p. 83), que

O Conselho é assim por definição um espaço institucionalizado para o engajamento da sociedade nos processos de decisão vinculados ao planejamento e à gestão democrática da unidade de conservação, uma instância formal de participação e controle social. Assim, um espaço de construção de governança, por excelência.

No termos desses autores, não há dúvida que a redemocratização do Brasil, que teve como consequência a Carta Magna de 1998, abriu por definitivo, um espaço de construção de uma governança; se bem orientada, tal mudança fortalece tomadas de decisões democráticas e legítimas para fins coletivos. A importância dos conselhos em um processo de gestão é transparente, apesar desses não serem de caráter deliberativo, mas apenas consultivos.

\section{Uma discussão sobre a teoria da ação coletiva}

Em um artigo seminal, de autoria de Garret Hardin, em 1968, que suscitou polêmicas, cujo título é The Tragedy of the Commons, este vai afirmar que a maximização de interesses individuais, por meio de uma ação racional não redunda em bem estar coletivo. Muito pelo contrário, o autor conclui que essa maximização terminaria em uma "tragédia dos comuns". A tese do autor é a que se segue maneira: pastores de ovelhas utilizam uma mesma área para a pastagem. Um dado pastor resolve adicionar ao seu rebanho mais uma unidade; o ganho gerado por 
essa adição não é repartido coletivamente, ficando somente com o dono daquele rebanho. No entanto, as despesas para manter as pastagens são divididas por todos.

Teoricamente, espera-se que cada indivíduo queira otimizar seu lucro aumentando ad infinitum seu rebanho, até o momento que os recursos que aquela pastagem comporta se esgotam, o que vai gerar uma tragédia para todos os pastores. O autor vai ainda ilustrar essa "tragédia" dando um exemplo dos parques nacionais, quando diz que

\begin{abstract}
En la actualidad están abiertos a todo el mundo sin restricción alguna. Sin embargo, los parques son limitados en extensión: solamente hay um parque nacional Yosemite, mientras que la población parece crecer sin limite. Los mismos atractivos que los visitantes buscan de los parques se desgastan de manera constante. Es evidente que debemos dejar de considerarlos como bienes comunes o dejarán de tener valor como tales.

¿Qué haremos? Tenemos sólo una alternativa: venderlos como propriedade privada o conservar su carácter público pero restringiendo el derecho de entrada (HARDIN, 1968, p. 14).
\end{abstract}

Nessa perspectiva, entende-se que para o autor há praticamente uma separação intransponível entre racionalidade individual e racionalidade coletiva. $O$ mesmo vai acrescentar que somente se pode conter uma tragédia por meio de dispositivos coercitivos e de leis, já que o autor não acredita na cooperação entre comuns. E mais, quando Hardin (1968) se refere a poder coercitivo, ele o faz de modo particular, especialmente com relação a que teoriza, ou seja, coerção não se coaduna com decisões de caráter arbitrário, e sim com acordos mútuos, que considerem a maioria dos atores em jogo.

A avançar-se nos entendimentos sobre o comportamento de grupos sociais (coletividades) com relação à gestão de bens comuns, passa-se a discorrer sobre o pensamento de Olson (1999), quando trata da ação coletiva. Esse autor vai afirmar que os indivíduos apenas se unem para cooperar se houver interesse pessoal. É este o motivo precípuo que move as pessoas em grupo quando se propõem a agir em prol de interesses coletivos. No entanto, o autor enfatiza sua premissa quando diz que

$\mathrm{Na}$ verdade, a menos que o número de indivíduos do grupo seja realmente pequeno, ou a menos que haja coerção ou algum outro dispositivo especial que faça os indivíduos agirem em interesse próprio, os indivíduos racionais e centrados nos próprios interesses não agirão para promover seus interesses comuns ou grupais (OLSON, 1999, p. 14).

Neste ponto, é de ressaltar-se que, dentro da lógica olsoniana, os atores sociais não elegem, ao tratar-se de bens comuns, não elegem apenas os incentivos de ordem econômica como razão para a cooperação. Atributos tais como laços de amizade, credibilidade e respeito podem muito bem constituírem-se como móveis para a ação coletiva, que, naturalmente, são pressupostos básicos da ação à 
cooperação. Além desses, o autor aventa a possibilidade de que sanções e recompensas outras levem à cooperação.

Ainda, os arranjos institucionais têm sido vistos como essenciais para que haja governança sobre os bens coletivos; assim, se evitam tragédias coletivas e entropias de recursos (OSTROM, 1990). Esta autora vai propor uma via que possibilita o estabelecimento de instâncias normativas e regulatórias visando ao uso de um bem comum que pressupõe a aquiescência de seus usuários. E não haveria necessidade para viabilizar a sustentabilidade do recurso para que 0 mesmo fosse privatizado ou estatizado. O que subjaz a essa estratégia ostromiana é que os usuários cooperariam devido ao interesse na conservação dos recursos, dos quais dependeria a vida comunitária e individual.

Ao aplicar-se o entendimento de ação coletiva de Ostrom ao turismo sustentável, Campos e Quaresma (2006) vão afirmar que

[...] faz-se necessária a participação efetiva dos diversos atores envolvidos na efetivação da atividade turística. Tal participação deve ser concebida no sentido da teoria da ação coletiva de Ostrom (op. cit), ou seja, a cooperação efetiva, cujos elementos centrais são reciprocidade, reputação e confiança. Em locais onde existem organizações comunitárias, associações, movimentos populares etc., as cooperações e organizações autogestoras são mais evidentes e ativas, isto é, conseguem manejar os recursos com pouca ou quase nenhuma intervenção do Estado. Portanto a cooperação proposta por Ostrom precisa existir efetivamente nas políticas públicas de turismo, sob pena de as tragédias dos bens comuns continuarem a inibir 0 verdadeiro processo de desenvolvimento (CAMPO; QUARESMA, 2006, p. 144).

Constata-se, portanto, que os autores referenciados nas análises de Ostrom (1990) afirmam que, segundo dadas condições, é possível uma governança eficaz e sustentável em torno da relação entre usuários e recursos comuns.

Por sua vez, Hardin, Olson e Ostrom não têm medido esforços para a compreensão dos dilemas sociais. Ostrom, com relação aos outros, avança, graças a uma pesquisa vasta de campo. Isso se dá quando constata que a autogestão em torno de recursos comuns e escassos tem como pressuposto a cooperação e desse modo pode evitar o conflito, o interesse individual egoísta e, ainda, redundar em soluções sustentáveis que beneficiem as realidades coletivas.

\section{A atuação do conselho consultivo no processo de governança do PARNAMAZONIA}

Os relatos oriundos das entrevistas realizadas em Itaituba - estado do Pará foram importantes com relação aos entendimentos sobre a participação (e não) na criação, gestão e turismo do PARNAMAZONIA. Dentro da gama de informações colhidas, passa-se, doravante, a destacar as que mais se sobressaíram no que se refere ao objeto de estudo, ou seja, aquelas que de uma maneira precisa foram fundamentais para responder acerca das inquietações da pesquisa.

\section{$A$ formação do Conselho e ações de turismo: problemáticas e perspectivas}


Por ocasião da criação do PARNAMAZONIA, nos idos de 1974 e sob o regime ditatorial, não havia espaço para a formação de CC em áreas protegidas, mesmo porque ainda não se tinha legislação regulamentada para isso. Vale ressaltar que em um relato colhido o entrevistado ${ }^{4}$ reporta-se ao momento histórico de sua criação:

[...] o parque foi instituído em 1974 ainda sob o regime militar, na presidência do Médici, na abertura da Transamazônica; então, eles acharam importante uma área de preservação e criaram o Parque Nacional (Informação verbal)

A partir dessa informação - e das demais de todos os outros entrevistados que trazem o mesmo teor -, depreende-se que, entre os membros que compõem o conselho ou mesmo entre os moradores da região, ninguém foi ouvido, o que não é de surpreender devido à conjuntura política à época.

Note-se que, nessas circunstâncias, não dá para pensar-se em governança de bens comuns a partir de uma teoria democrática e participativa como a da ação coletiva de Ostrom que prevê, sobretudo, para a realização de fins coletivos a cooperação entre todos os atores interessados. Em contextos de arbitrariedades (que pressupõe coerção) não há como aventar-se tal possibilidade. Nesse sentido, essa UC já nasce com o "pé quebrado" e passível de alguma tragédia ambiental. E melhor (ou pior), o processo já se instaura com relação à coletividade e ao meio ambiente, de modo deseducativo e desagregador, o que vai influenciar na sua sustentabilidade futura e em distanciamento simbólico perigoso entre os convivas que se relacionam direta ou indiretamente com o PARNAMAZONIA.

Essa análise procede e é por demais visível por demais, em especial quando se atém às declarações de César Haag ${ }^{5}$ que informa sobre o distanciamento entre comunidade e parque. Tal ocorre, embora esteja a menos de $100 \mathrm{~km}$ de Itaituba. As pessoas não tinham ideia do que seria um parque, apesar de frequentarem as corredeiras que ali se encontram; ignoravam que o lugar era de uso público. Essa dissociação é percebida até hoje e se constitui, portanto, em uma relação de afastamento, de exclusão. Tal observação é reiterada pelas autoras, pois diversas vezes, sempre que se perguntava aos moradores do município sobre o parque, eles afirmavam que em sua maioria nunca tinham ido ao parque.

Nesse sentido, o entrevistado afirma que o trabalho da AMIPARNA foi muito importante, pois a citada associação levava

[...] os ônibus cheios de crianças das escolas para o parque, e diziam que aqui é um espaço público, no sentido amplo do público, que podem visitar, podem aprender coisa sobre a biodiversidade da região de vocês, pois o que se ensina hoje na escola é o e de elefante, mas tem elefante aqui na Amazônia? Tem? Não tem elefante aqui. É fundamental que se aprenda o $a$ da arara, o $m$ do macaco, da nossa fauna que está viva. [...]. (Informação verbal).

Depreende-se daí, que urge a necessidade de se trabalhar, a partir do ensino fundamental, a questão da educação e interpretação ambiental, no sentido de mudança, tendo como referência o discurso acima, ou seja, essa separação entre natureza e cultura, o que está, segundo ainda o entrevistado, na formação do ser 
social local, regional. Todavia, é importante que esse processo educativo ambiental seja estendido também para todos os atores sociais que, de um modo ou de outro, estejam ligados ou frequentem o parque.

No que concerne à formação propriamente dita do CC do PARNAMAZONIA, esta se deu somente em 2004, baseado na lei do SNUC (2000), art. 29, já citada anteriormente, que obrigava a constituição de CC no processo de gestão do parque. O depoimento a seguir revela de que modo as pessoas da localidade mantiveram um primeiro contato com a ideia de participação enquanto conselheiros da UC em questão, que há mais ou menos trinta anos havia sido criada:

[...] nós vimos a nos familiarizar ou a ingressar no grupo de estudos, debates dentro do parque nacional, quando da vinda da Livia, exgestora do parque, para a formação do conselho consultivo, praticamente depois de duas décadas; o conselho começou a ser fomentado para elaboração do plano de manejo do parque foi quando nós tivemos as capacitações da $\mathrm{Cl}$ [...], a chefe do parque na época começou a trabalhar com a questão da participação das comunidades; então foram incluídas as comunidades do entorno e de dentro do parque para fomentar o plano de manejo, que só podia ter três ações básicas; então foram reunidas as comunidades e depois dessas reuniões surgiram as ações prioritárias, que era a formação do conselho, as capacitações comunitárias e a busca de recursos para implementar o uso público do parque como eles chamavam. (Informação verbal, José Santos Nascimento Filho, representante da AMIPARNA).

Com esse depoimento, é de notar-se que já nos primeiros momentos de discussão e tentativa de organização para uma gestão compartilhada ficava evidente que o "projeto" não era uma unanimidade com relação a determinados atores porque ia contra seus interesses individuais.

Assim, a reunião de atores sociais para a constituição do conselho, embasada em lei - representa a própria gênese do processo de governança no parque, ou seja, é seu marco regulatório. Nesse contexto, há de se apontar o fato de que esse movimento de articulação com vistas à formação do CC emana de uma instância governamental, o IBAMA, que à época era o gestor da UC, e não do seio da sociedade civil. Sem dúvida, ligado a isso, é de se pensar que talvez o parque não constitua um bem para a comunidade - ou talvez algo que porventura esteja distante subjetivamente e que por isso mesmo não se constitui como um concreto -, parece que a mesma não consegue dimensionar toda a sua importância, em vários níveis, como exemplos ambientais, socioeducativos e histórico-culturais.

O processo de governança no PARNAMAZONIA pelas informações colhidas indicava ser promissor, principalmente no que diz respeito aos seus primórdios, quando da formação do CC, isto é, havia um projeto de ações a serem realizadas. E algumas o foram, como exemplificam os esforços para propiciar o uso público do parque, e para isso foi constituída a AMIPARNA, fruto "[...] de uma dessas capacitações realizadas inicialmente com o intuito de levar os alunos do município para conhecer o parque nacional" (Informação verbal). Sem dúvida, só vem a comprovar as boas intenções dos atores sociais partícipes do conselho com relação a uma boa governança do parque. 
É importante ressaltar que foram empreendidas outras ações que foram destaque no que tange ao turismo no parque. $O$ depoimento a seguir retrata muito bem isso:

[...] a partir de 2007, com o projeto corredor Tapajós-Abacaxis que pretendia apoiar a implementação de quatro unidades de conservação naquela região, o Parque Nacional da Amazônia, a Flona do Amanhã, a RESEX Tapajós-Arapius e a Flona Pau-Rosa. E o objetivo era desenvolver um instrumento de gestão das UC's, pois nenhuma tinha plano de manejo nem conselho. Então, basicamente, o que fizemos foram muitas pesquisas (NR) para subsidiar a elaboração dos planos de manejos e a construção e capacitação dos conselhos. Entretanto, no PARNAMAZONIA teve um plus. Nós apoiamos ainda o fortalecimento da AMIPARNA, pois estrutruramos sua sede e financiamos algumas ações de educação ambiental; e investimos também em infraestrutrura, como a trilha interpretativa e o mirante, que foram financiados por este projeto do corredor tapajós-abacaxis. (Informação verbal, César Haag).

O CC configura-se também a partir desse depoimento como uma entidade ativa, preocupada com os rumos do parque, e para isso buscando e conquistando parceiros, convidando-os para os cuidados com o bem coletivo. Denota-se, cabalmente, o trabalho desenvolvido pelos conselheiros, disseminando inclusive informações na comunidade e em seu entorno ao ponto de contagiar outros atores com relação à importância dessa UC para a região. $O$ relato seguinte deixa isso bem claro:

Financeiramente, a gente não participou da estruturação física do parque, mas ajudou a refletir as trilhas e o mirante, qual seria 0 melhor local, que tipo de estrutura seria viável. Um exemplo foram aqueles bancos em forma de onça, dando um recorte para a floresta, uma valorização diferenciada do tipo de móvel, então foi o IPAM que orientou a $\mathrm{Cl}$, onde ela deveria comprar, fizemos a interlocução com os outros moradores da FLONA do Tapajós, oficinas caboclas do Tapajós. A Instituição que executou foi a AMIPARNA na época. (Informação verbal, Edivan Silva de Carvalho, representante do Instituto de Pesquisa da Amazônia (IPAM)).

Nesse sentido, o conteúdo dessas entrevistas é imprescindível para se compreender os momentos iniciais da atuação e envolvimento de determinados atores sociais com relação à governança ambiental e às ações no que concerne ao turismo no parque.

Apesar das constatações averiguadas no parágrafo acima - construção de uma governança e advento do turismo no parque -, evidencia-se, segundo a pesquisa, a configuração de um cenário que praticamente descontrói o anterior.

Isso se verifica por meio de problemas que foram ressaltados por todos os personagens do conselho e que configuram um quadro de descontinuidades, descompromissos, entre outras falhas, que vão descaracterizar a importância dessa instância no âmbito do processo de governança da UC. Para iniciar essa 
discussão, veja-se, espécies de relatos que vão mostrar de modo contundente como ocorre essa desarticulação:

O conselho há dois anos faliu; os representantes do ICMBIO [...] eles descasaram, e o Conselho se desmotivou, a gente, não está mais funcionando esse Conselho. (Informação verbal, Isaías Soares de Oliveira, representante do Sindicato de Trabalhadores e Trabalhadoras Rurais de Itaituba - STTR, grifo das autoras).

Faz muito tempo que nós não recebemos nada de comunicado do conselho. Na verdade, eu acho que o conselho está desativado, ele não está funcionando [...]. (Informação verbal, Ana Denise Azevedo Paxiuba, representante da Associação dos Filhos e Filhas de Itaituba - ASFITA, grifo das autoras).

Normalmente, participamos quando somos convidados. Agora eu não sei se ainda sou do conselho. Mas como conselho do parque, nunca mais se reuniu. (Informação verbal, Reinaldo José Barbosa Lira, representante da Indústria de Cimentos ITACIMPASA, grifo das autoras).

Está zero. A gente nunca mais foi notificada, quer dizer, a não ser o sargento Anael, porque eu fui destacado em dois anos. (Informação verbal, Raimundo Nonato Leal da Ressureição, representante do 15․ Batalhão da Polícia Militar do Estado do Pará, grifo das autoras).

A participação nossa no conselho está um pouco parada, porque a gente é convidada; o conselho envia os convites para as reuniões e no momento a gente está ausente por falta de reuniões do conselho mesmo.(Informação verbal, Jesielita Roma Gouveia, representante do Fórum dos Movimentos Sociais da BR-163, Km 30, Campo Verde (Distrito), grifo das autoras).

Ele está desativado, até porque a responsável pelo parque, que era do conselho consultivo, que dava a maior força, ela foi transferida, que era a Maria Lúcia. E depois que ela saiu, nós não tivemos mais reuniões; estão faltando essas reuniões. (Informação verbal, Ana Aparecida Melo Baima, representante da Empresa de Assistência Técnica e Extensão Rural do Estado do Pará EMATER, grifo das autoras).

Nesse sentido, para que se compreenda o nível de esfacelamento em que se encontra o que teria que ser o conselho do PARNAMAZONIA, há de atentar à legislação sobre a estruturação e a consolidação de um CC de uma UC.

Assim, de acordo com Brasil (2004 apud Irving; Loureiro, 2007), compete ao conselho não apenas o que na lei está expresso, que diz da elaboração do regimento interno, da avaliação de orçamentos e contratos, do acompanhamento da elaboração e revisão de planos de manejo, bem como dar continuidade às ações que visem a sustentabilidade nas UC. E mais, um CC precisa ser criado tendo como 
fim o estabelecimento de uma mobilização ampla dos atores sociais, o pleno conhecimento da dimensão ambiental e social da UC; e, finalmente, a organização sistemática de encontros para tomada de decisões que digam respeito ao objeto de seus cuidados.

Conclui-se, ao comparar-se o que a legislação ordena com o que se constata na realidade, que o conselho do PARNAMAZONIA - além de não funcionar como deveria, ou seja, regularmente - parece que as perspectivas que o venha a fazer estão distantes. Isso se deve, portanto, à desorganização profunda e, segundo os relatos acima, por falta de convocação do ICMBIO, como se este fosse o único responsável para articular as reuniões. Esse segundo motivo fica mais evidente com a leitura do relato a seguir:

Ficou um pouco complicado para participar porque o ICMBIO está passando por uma série de mudanças. Nós tínhamos uma chefia dentro do parque, essa chefia saiu e ficou o colega Sales e agora sabemos que mudou novamente. (Informação verbal, José Santos Nascimento Filho, representante da AMIPARNA).

Então, os depoimentos relativos a atual participação dos membros do conselho denota um estado de desânimo e de falta de pertencimento, além de parecer que desconhecem seus direitos de se autogerirem dentro de contextos determinados, como por exemplo, o de não esperar por uma convocação, tomando atitudes próprias que visem o interesse coletivo.

Com respeito às razões da desarticulação das reuniões no sentido de participação, há um leque bem aberto de explicações, que parecem fazer sentido. Vejam-se alguns depoimentos que vão justificar, segundo seus autores, essa situação, pois apontam precisamente sua inação:

É que o conselho é consultivo; na verdade o conselho é para ser renovado no próximo mês; Só não foi dado continuidade no passado em função da lei que desafetou o parque; como houve a saída da chefe no ano passado, em 2012, faltou uma reunião. Eu pretendo renovar o conselho agora em 2013. O conselho não está desativado, na verdade, é que os conselheiros não são atuantes. (Informação verbal, Assor Egon Fucks, chefe do PARNAMAZONIA e representante do ICMBIO).

Esse ano nós não fomos convidados a participar de reunião do parque porque houve uma mudança na gerência, então eu acredito que $o$ atual gestor quando tiver total conhecimento, funcionamento e seus instrumentos e em que pé anda, eu acredito que ele vai realizar essas reuniões. (Informação verbal, Erotildes Santos Rodrigues, representante da Secretaria Municipal de Meio Ambiente de Itaituba - SEMMA).

[...] o parque nacional tem gerado um conflito ou pelo menos gerou um conflito em função da ocupação da área que ele ocupava, que não tinha divisas naturais, e de pessoas que ocupavam o parque e foram retiradas, pessoas de influência e de certa forma com algum tipo de violência; e das reuniões que o IPAM participou estava muito fragilizado, por isso as reuniões estavam se esvaziando. 
(Informação verbal, Edivan Silva de Carvalho, representante do IPAM).

Eu acho que se deve à troca de gestor; nós estávamos na gestão da Maria Lúcia, depois passou para o Sales assumir interinamente e agora é o Assor. Essa mudança de gestão desarticula as ações prioritárias de reuniões do conselho [...]. (Informação verbal, José Santos Nascimento Filho, representante da AMIPARNA.

O conselho vinha funcionamento assim uma média mais para o lado dos empresários do que para os agricultores; quando a gente ia se reunir, a maioria dos governamentais, da sociedade civil era mais forte de que as cadeiras de agricultores; eles pouco atendiam os agricultores. (Informação verbal, Isaías Soares de Oliveira, representante do STTR).

O conselho, eu não posso nem lhe alegar muito porque a gente aqui no trabalho, muitas vezes no dia a dia, às vezes, se não tiver algum lembrete, a gente se esquece, mas eu como conselheiro, senti muito a retirada do IBAMA. (Informação verbal, Francisco Afrânio Nunes, representante da Fundação Nacional do Índio FUNAI).

Eu acho que as políticas do governo estão atrapalhando um pouco essas reuniões com os conselheiros do parque; muda de governo, aí muda a administração, o ICMBIO muda a coordenação. (Informação verbal, Jesielita Roma Gouveia, representante Fórum dos Movimentos Sociais da BR-163, Km 30, Campo Verde Distrito)

Quando foi criada a AMIPARNA, o conselho perdeu um pouco, para não dizer totalmente o objetivo, aí suspenderam as reuniões, nós não fomos mais convidados. A AMIPARNA pegou a responsabilidade para ela; foi ela que ficou responsável por tudo que era decidido. (Informação verbal, Ana Denise Azevedo Paxiuba, representante da ASFITA).

Faz tempo que não somos convocados para reuniões. Só fomos convocados na época quando foi criado o conselho, inclusive para visitas no parque, aquela coisa, quando estavam para se criar as outras unidades de conservação, porque tinha dinheiro da ONG de fora. (Informação verbal, José Antunes, representante da Associação dos Mineradores de Ouro do Tapajós - AMOT).

Eu acho que é por causa da mudança assim, de os funcionários que vêm de fora; chegam aqui é uma realidade diferente, e eles têm boa vontade para fazer alguma coisa. (Informação verbal, Ana Aparecida Melo Baima, representante da EMATER).

Isso tem resultado, entre outras coisas, no não usufruto devido aos comunitários locais e turistas desse bem comum; no "fortalecimento" do sentimento de não pertencimento em relação ao parque por parte das pessoas da região; na falta de exploração daquele espaço pelas escolas da região como apoio para uma educação ambiental; e na não concretização como área lúdica. Para efeito de didatismo na explicação, passa-se a elencar, segundo os depoimentos acima, os motivos centrais que fragilizaram o conselho do PARNAMAZONIA. Todos têm seu grau de importância, mas é no relacionamento entre eles que se observa quão 
instável se mostra o conselho em relação às ações em benefício do parque, que deveriam empreender.

Em primeiro lugar, é de se entender o significado real de um CC que se atente para o fato de que

[...] conselhos gestores devem ser entendidos como espaços legalmente constituídos e legítimos pra o exercício do controle social na gestão do patrimônio natural-social, e não apenas como instância de consulta dos gestores e das gestoras e/ou equipe técnica envolvida (IRVING, 2005, p. 18).

Nesse sentido, não é o que parece compreender o então presidente do conselho e gestor do parque ao afirmar, quando perguntado sobre a atual situação do conselho, que o mesmo era consultivo. Relacionadas a isso, estão questões como a necessidade de renovação do conselho, mudança de gestor, saída do IBAMA da cidade, falta de logística ocasional para reuniões, sem falar na dependência também para isso de recursos provenientes das ONG, lentidão burocrática, entre outros, não poderiam ser empecilhos e entraves para o desmonte do CC no que havia de sólido.

A seguir, outros fatores são pontuados também pelos depoentes como causadores dos desenlaces dessa instância de poder. Devido a uma discussão de uma pauta que se referia a uma área de demarcação do parque, que é conflituosa, a participação nas reuniões começou a decair, principalmente porque as discussões não avançaram e, por isso, não resultaram em um planejamento resolutivo que trouxesse benefícios à UC no que respeita ao turismo. Ainda, temse a alegação de um entrevistado de que no próprio conselho há uma tendência de se privilegiar conselheiros empresários a membros agricultores: o poder da AMIPARNA a direcionar pautas de "compromissos", causando desconforto entre uns e outros membros; mudança de governo, causando remanejo de servidores, tendo reflexos no método de trabalho da gestão.

E, sobretudo, o advento da questão energética quando foi divulgada amplamente a instalação do complexo hidrelétrico do Tapajós, e que para isso uma parte do parque foi desafetada, causando uma série de conflitos de ordens diversas. E, por conseguinte, atingindo, de uma maneira ou de outra, membros conselheiros, bem como a população, o que também redundou em desmotivação.

É evidente que os problemas concernentes ao conselho não podem ser separados dos do parque, visto que antes da existência do conselho, a UC já existia concretamente. E trazia desde a sua origem toda outra série de problemas de naturezas diversas, que ficaram latentes e historicamente foram emergindo, manifestando conflitos os mais variados, de cunho social, político, econômico, agrário, étnico e ambiental.

E mais, outros problemas relativos ao território do parque como ao seu entorno foram também detectados; e faz-se referência à falta de estrutura no sentido lato da palavra, inclusive turística, que inviabilizaria o desenvolvimento de atividades em termos científicos, educativos e recreacionais. 
E apesar do projeto dessa fonte energética ainda não ter se concretizado, vem causando polêmicas, tensões e conflitos envolvendo atores diversos, que de várias maneiras influenciam os caminhos presentes e futuros do PARNAMAZONIA.

Para fechar esse quadro de causas e consequências responsáveis pelos destinos do PARNAMAZONIA, veja-se um depoimento que chama bastante atenção no que respeita à "visão de parque" que o atual gestor tem:

Pelo tempo que o parque existe, não houve nenhuma ação para desenvolver o turismo e, eu acredito que não haverá, porque como gestor e tendo uma visão mais espacial do parque, o parque estava no plano de ser utilizado para complexo hidrelétrico; então eu não vou investir em uma UC que vai ser utilizada para ser construída uma hidrelétrica. Eu até já falei que ele poderia até trocar de categoria, porque não tem uma visitação significativa, por isso poderia ser uma Reserva Biológica. (Informação verbal, Assor Egon Fucks, chefe do PARNAMAZONIA e representante do ICMBIO).

Na sua lógica "espacial", que parece especialmente frágil, o gestor quer justificar as transformações que possam vir a acontecer na estrutura territorial do parque, o que naturalmente vai incidir, provavelmente de modo negativo, sobre um turismo ainda muito incipiente.

\section{Conclusão}

Ao longo do tempo, a riqueza da Amazônia brasileira vem sendo explorada de modo mercantil por outras nações e a seu modo e a sua época. Mas é somente no final do século XX que essa região passa a ser foco de interesses do capitalismo internacional quando este se reestrutura em termos de globalização. Então, é a partir desse momento que a biodiversidade amazônica passa a ser inextricavelmente (e ideologicamente) ligada ao conceito de desenvolvimento sustentável planetário, e por isso sofre os efeitos de uma tentativa de política de governança ambiental global. Nesse contexto, salienta-se que emerge no Brasil um processo incipiente de governança ambiental local em contraponto à global como estratégia de defesa do seu meio ambiente, impulsionado pelos movimentos sociais organizados, entre outros atores.

Em face a essa tentativa de institucionalidades novas e a ter por base os dados da pesquisa no que se refere ao PARNAMAZONIA, afirma-se que, em seus primórdios, se CC foi ativo, participativo e apresentou resultados concretos segundo uma ordem de governança estabelecida - que resultaram em ações voltadas para o turismo. E nesse contexto, sobressaíram-se algumas ONG, desempenhando o papel de articuladores com o fito de se implantar uma estrutura mínima para o uso público do parque, apoiadas, por instituições governamentais que foram sobremodo importantes para esse início de processo. Esse quadro de realização deu-se, sem dúvida, graças à sinergia dos diferentes atores em torno do objetivo comum que era a estruturação turística da UC.

Portanto, tudo se encaminhava, para uma consolidação institucional dessa instância, apesar das dificuldades conjunturais, administrativas, burocráticas, de disputa de poder, entre outras. Mas eis que incide sobre essa governança positiva um fato que vai fraturar uma harmonia possível: a irrupção do processo que cria o 
complexo hidrelétrico do Tapajós. Então, emerge daí uma série de falhas nas articulações que propiciavam a atuação do conselho com ações de consequências benéficas para o PARNAMAZONIA.

Apesar da área onde se circunscreve o parque historicamente ter sido palco de conflitos de terras entre as comunidades locais, que já habitavam o parque antes do mesmo ser criado, com a desafetação de uma fração da UC supostamente para a construção da hidrelétrica, os conflitos se acirraram, o que se refletiu negativamente na atuação do conselho.

Pode-se pensar também que o fato anunciado da instalação da hidrelétrica tenha gerado uma desmotivação substancial, que evidencia a falta de pertencimento do parque para com a comunidade. As pesquisam revelam que mesmo diante da anunciação de que uma parcela do parque seria inundada, não houve uma reação no sentido de fortalecimento do corpo do conselho para discutir e se inserir como poder no enfrentamento dessa questão. Como era de ser esperar, iria prejudicar tanto o parque, enquanto espaço de preservação ambiental, como as comunidades do entorno da UC

Por fim, diante de questões tão sérias como a preservação de uma UC para o país, é necessário que se repense o significado de conselho gestor, não como uma instância apenas consultiva ou deliberativa, não se trata disso. O que importa na verdade é que os atores se fortaleçam, aproveitando constitucionalmente 0 espaço democrático para agir e não ficarem a mercê de verticalidades de poder, o que é nefasto para uma democracia que se pretenda amadurecer. Talvez, em assim fazendo, possam contribuir para evitar as mais diversas tragédias coletivas.

\section{Referências bibliográficas}

ANDRADE - MENDONZA, K. Introducción. In: .(Org.). Gobernanza ambiental en Bolívia y Perú. Gobernanza en tres dimensiones: de los recursos naturales, la conservación en áreas protegidas y lós pueblos indígenas. Quito: FLASCO, Sede Ecuador; UICN, 2011. p. 15-24.

ARAUJO, R. B.; CASTRO, E. Belém dos conselhos: arranjos democráticos e tensões na formulação e gestão de políticas municipais. In: CASTRO, E. et al. (Org.). Atores sociais, trabalho e dinâmicas territoriais. Belém: NAEA; UFPA, 2007. $341 \mathrm{p}$.

BECKER, B. K. Amazônia: geopolítica na virada do III milênio. Rio de Janeiro: Garamond, 2004, 168 p.

BRASIL. Constituição (1988). Constituição da República Federativa do Brasil: promulgada em 5 de outubro de 1988. 21. ed. atual. e ampl. [São Paulo]: Saraiva, 1998. 267 p.

CAMPOS, R. I. R.; QUARESMA, H. D. A. B. Turismo como instrumento de ação coletiva em áreas pesqueiras do litoral da Amazônia. Bol. Mus. Para. Emílio Goeldi. Ciências Humanas, Belém, v. 1, n. 2, p. 139-147, maio-ago. 2006.

DE ANTONI G. O. Programa Piloto para Proteção das Florestas Tropicais do Brasil (PPG7) e a globalização da Amazônia. Ambiente \& Sociedade. Campinas, v. XIII, n. 2 p. 299-313, jul.-dez. 2010.

ESTRATÉGIA de Uso Público: Parque Nacional da Amazônia. Consultoria de Milton Dines. São Paulo: MMA; SEDR; PROECOTUR; ICMBio; 
PNUD, 2009. Projeto BRA/99/009/1. Contrato nº. 2007/000898. Termo de Referência n‥ 125532: Consultor UP PARNA Amazônia.

FEARNSIDE, P. Hidrelétricas amazônicas e política energética 3: impactos de barragens em séries. Disponível em:<http://g1.globo.com/platb/naturezaphilipfearnside/. Acesso em: 18 jan. 2011.

FUENTES, J. L. Gobernanza para la conservación de áreas protegidas. In: ANDRADE-MENDONZA. K. (Org.). Gobernanza ambiental en Bolívia y Perú: gobernanza en tres dimensiones: de los recursos naturales, la conservación en áreas protegidas y los pueblos indígenas. Quito: FLASCO, Sede Ecuador; UICN, 2011. p. 85-115.

GOHN, M. G. Conselhos gestores e participação sociopolítica. São Paulo: Cortez. 2003.

HARDIN, G. La tragedia de los bienes comunes. 1968. Disponível em:<http://nocionescomun es.files.wordpress.com/2013/02/2804.pdf. Acesso em: 10 abr. 2014.

INSTITUTO CHICO MENDES DE CONSERVAÇÃO DA BIODIVERSIDADE (ICMBIO). Quadro demonstrativo de visitação turística do PARNAMAZONIA. Itaituba (PA), 2014.

INSTITUTO SOCIOAMBIENTAL (ISA). Disponível em: <http://uc.socioambiental.org /uc/481>. Acesso em: 2 jan. 2011.

IRVING, M. A., et al. Governança e políticas públicas: desafios para a gestão de parques nacionais no Brasil. 2005.2 Disponível em:<http.flacsoandes.org.web/imagesFTP/8679.05.Governanza_y_politicas_publi cas_desafios_para_la_gestion_de_parques_nacionales_en_Brasil.pdf>. Acesso em: 13 nov. 2011.

IRVING, M. A.; LOUREIRO, C. F. B. Gestão participativa em unidades de conservação. Rio de Janeiro: IBASE, 2007. Disponível em: <www.ibase.br>. Acesso em: 10 jan. 2013.

JACOBI, P. R.; SINISGALLI, P. A. de A. Governança ambiental e economia verde. Ciências \& Saúde Coletiva, v. 17, n. 6, p. 1469-1478, 2012.

KASECKER, T.; SILVA, J. M. C. Parque Nacional da Amazônia. In: VALENTE, R. et. al. (Org.). A conservação de aves migratórias nearticas no Brasil. Belém: Conservação Internacional, 2011. p. 92-99.

NASCIMENTO, V.L.Q.; SIMONIAN, L.T.L. A política de ecoturismo no pólo Belém/Costa Atlântica (PA). Revista Brasileira de Ecoturismo, São Paulo, v.7, n.3, ago/out 2014, p. 618-645.

OLSON, M. A lógica da ação coletiva: os benefícios públicos e uma teoria dos grupos sociais. São Paulo: EDUSP, 1999.

OSTROM, E. Governing the commons: the evolution of institutions for colletive action. Cambridge: Cambridge University Press, 1990.

SILVA, A. T. Segurança multidimensional e governança do desenvolvimento sustentável na Amazônia brasileira. In: ROCHA, G. de M. et al. Governança, integração e meio ambiente na Amazônia. Belém: NUMA; UFPA, 2007. p. 67-97. 
VIOLA, E. A. globalização da política ambiental no Brasil, 1990-1998. In: International Congress of the Latin America Studies Association, 21., 1998. Chicago. Disponível em: <http://lasa.international.pitt.edu/LASA98/Viola.pdf>. Acesso em: 31 mar. 2014.

\section{Notas}

'Segundo Fearnside (2011), esta UH terá capacidade (MW) de 6.133, sua área do reservatório (ha) 72.225 e área inundada de UC (ha) 30.251. Hidrelétricas amazônicas e política energética 3: impactos de barragens em séries.

Entendida como um meio para assegurar a conservação. Está referida aos marcos normativos e às políticas ambientais, que, por sua vez, devem atender às necessidades da população, à consolidação de espaços democráticos, conservação da biodiversidade e manejo dos ecossistemas. (ANDRADE-MENDONZA, 2011, p. 20).

${ }^{3}$ Pode definir-se como as formas de governo, autogoverno e exercício autônomo dos povos indígena em definir sua própria vida social e política sob os mais diversos aspectos (estrutura organizativa, instituições, regras e mecanismos de controle social, entre outros). (FUENTES, 2011, p. 118).

${ }^{4} J o s e ́$ Santos Nascimento Filho, representante do AMIPARNA.

${ }^{5}$ (Informação verbal); representante da Conservação Internacional (CI).

Monica de Nazaré Ferreira Araújo: Universidade Federal do Maranhão, São Luís, MA, Brasil.

E-mail: monica.nazare@ufma.br

Link para o currículo Lattes: http://lattes.cnpq.br/9650733523825165

Ligia Terezinha Lopes Simonian: Universidade Federal do Pará, Belém, PA, Brasil.

E-mail: simonianl@gmail.com

Link para o currículo Lattes: http://lattes.cnpq.br/6620574987436911

Data de submissão: 04 de abril de 2015

Data de recebimento de correções: 04 de maio de 2016

Data do aceite: 04 de maio de 2016

Avaliado anonimamente 